\title{
LETRAMENTO INFORMACIONAL E FORMAÇÃO DE PROFESSORES: UM OLHAR SOBRE OS LICENCIANDOS DOS CURSOS DE LICENCIATURA DO INSTITUTO FEDERAL DE RONDÔNIA
}

\author{
Jussara Santos Pimenta \\ Doutora em Educação \\ Programa de Pós-Graduação em Educação Escolar - PPGEE/MEPE \\ Universidade Federal de Rondônia (UNIR) \\ jussara.pimenta@unir.br \\ Miriã Santana Veiga \\ Mestre em Educação \\ Bibliotecária-Documentalista \\ Instituto Federal de Ciência e Tecnologia de Rondônia (IFRO) \\ miria.veiga@ifro.edu.br \\ Suelene da Silva Batista \\ Mestre em Educação \\ Pedagoga Supervisora \\ Instituto Federal de Rondônia - IFRO. \\ suelene.batista@ifro.edu.br
}

\section{Resumo}

Este estudo apresenta a pesquisa realizada com oitenta e seis estudantes dos cursos de licenciatura ofertados pelo Instituto Federal de Educação, Ciência e Tecnologia de Rondônia (IFRO) e que fazem parte do Programa Institucional de Bolsas de Iniciação à Docência (PIBID). Analisa os conceitos de letramento e letramento informacional e discute a sua relação com a Formação de Professores. Como instrumento de coleta de dados foram utilizados questionários com perguntas abertas e fechadas aplicados aos estudantes bolsistas do PIBID. Como resultado da pesquisa, observou-se que mesmo utilizando métodos tradicionais como fontes de informação, como por exemplo o livro didático, parte dos futuros docentes, demonstraram que estão inseridos na Sociedade da Informação e que possuem um interesse maior, no uso de diferentes fontes de informação. Entretanto, parte dos licenciandos ainda mantém o tradicional uso da informação, com foco exclusivo no livro didático, o que norteia a necessidade da aplicação de práticas que auxiliem o futuro docente no uso letrado da informação.

Palavras-chaves: Letramento Informacional. PIBID. Instituto Federal de Educação de Rondônia.

\section{INTRODUÇÃO}

Vivemos na chamada sociedade do conhecimento ou sociedade da informação que exige dos cidadãos multiletramentos. Além do mínimo exigido, que seria o letramento da língua, ou seja, a escrita e a alfabetização, o mundo da informação estabelece que se alcancem outros letramentos como, por exemplo, o letramento informacional, voltado para o uso competente da informação e o letramento digital que trata sobre as "[...] práticas sociais de leitura e produção de textos em ambientes digitais" (RIBEIRO; COSCARELLI, 2018).

O período entre as décadas de 1960 e 1970 foi marcado pelo início dos estudos da oralidade e da escrita pelos pesquisadores educacionais. Os primeiros trabalhos publicados que questionaram a importância da cultura oral e escrita surgem na década de 1960 de século XX, com McLuhan (1972), no Canadá, e Lévi-Strauss na França (1970). Esses estudiosos buscavam entender a importância da oralidade sobre os processos de 
escrita e sua relevância na formação dos estudantes, algo que deveria ser respeitado na formação escolar dos mesmos, haja vista que antes da escrita vem a oralidade e que o processo de escrita e de alfabetização dos estudantes perpassa pela oralidade.

A palavra oralidade é um substantivo feminino, que significa: "qualidade, estado ou condição do que é oral" (Aurélio, 2017). Também podemos utilizar o termo para designar povos ágrafos, isto é, povos que não apresentam sinais gráficos, ou utilizam a escrita. O termo oralidade surgiu no século XX considerando a importância de se observar a oralidade no processo da formação de sociedades que usam a escrita. De acordo com Averlock (1997):

Atualmente, as expressões oralidade $\mathrm{e}$ oralismo têm sentido diferente, expressando conceitos que já se estenderam para além de Homero e dos gregos. Caracterizam sociedades inteiras que têm se valido da comunicação oral, dispensado o uso da escrita. E por fim são usadas para identificar um certo tipo de consciência, que se supõe criada pela oralidade ou que pode se expressar por meio dela. Esses conceitos tomaram forma à medida que se opuseram à cultura escrita, também considerada como condição social e estágio mental (HAVERLOCK, 1997, p. 1).

O termo "escrita" é um substantivo feminino e quer dizer: a representação da linguagem falada por meio de signos gráficos (Aurélio, 2017). A tecnologia da escrita fez a humanidade florescer, pois por meio dela e dos suportes informacionais (rolos de papiros, códex, livros, web textos, etc.) foi possível guardar e manter informações. Apesar da grande importância da escrita na vida dos estudantes, não podemos nos esquecer da importância da oralidade na sua formação, pois é por meio dela que os primeiros aprendizados ocorrem e se fortalecem. Como afirmava Vygotsky, a formação da criança não é feita exclusivamente pela escola.

A situação social de desenvolvimento é o ponto de partida para todas as mudanças dinâmicas que se produzem no desenvolvimento durante o período de cada idade. Determina plenamente e por inteiro as formas e a trajetória que permitem a criança adquirir novas propriedades da personalidade, já que a realidade social é verdadeira fonte do desenvolvimento, a possibilidade de que o social se transforme em individual (VYGOTSKI, 1996, p. 264).

Ela começa em casa e a oralidade é uma dessas etapas cruciais na formação do estudante, pois essa formação passa pela escola que ensina a criança a linguagem escrita e o aprimoramento da linguagem oral. No uso dessas habilidades a criança avança em seu letramento que ocorre de formas distintas para cada ser humano. Mesmo que a escola interfira e tente padronizar esta forma de letramento, cabe à criança ir interpretando e aprendendo conforme seu aparato cultural e social. Após ser letrada a criança se insere no mundo da informação, que pode ser oferecido a ela por meio da escrita, da leitura e também pela própria oralidade e assim, vai construindo o seu conhecimento científico, cultural e social.

\begin{abstract}
Quando se pretende que o aluno construa conhecimento, a questão não é apenas qual informação deve ser oferecida, mas, principalmente, que tipo de tratamento deve ser dado à informação que se oferece. A questão é então de natureza didática. Nesse sentido, a intervenção pedagógica do professor tem valor decisivo no processo de aprendizagem e, por isso, é preciso avaliar sistematicamente se ela está adequada, se está contribuindo para as aprendizagens que se espera alcançar (PCN, 1997, p. 38).
\end{abstract}

Por conseguinte, observamos a importância e a atenção que deve ser dada à linguagem oral e escrita na infância, pois ela é a base para todos os outros letramentos que o educando(a) receberá em sua formação escolar/acadêmica e que poderá influenciar em toda a sua vida, pois, o processo de aprender ocorre em todas as etapas do ciclo de vida do ser humano.

O caminho da humanização e da sustentabilidade exige que os agentes de aprendizagem sejam capazes de transformar as formas de gestão social do conhecimento para colocá-las à disposição de todos, sem exclusões. Isso implica a necessidade de as pessoas aprenderem a buscar e usar a informação para transformá-la em conhecimento em prol da vida. Não há conhecimento sem considerar as experiências pessoais e as informações. Nesses termos, a infraestrutura de informação da sociedade possui papel crucial em seu desenvolvimento. Inclui, pois, acesso à internet, aos museus, 
arquivos, centros de documentação e às bibliotecas (GASQUE, 2012, p. 151).

De todos os letramentos que uma criança deve aprender, um deles é o Letramento Informacional, pois não basta apenas saber ler e interpretar a informação é preciso saber usálas com ética, responsabilidade e qualidade. Sendo assim, os futuros professores têm uma grande incumbência dentro da sociedade informação, que é se responsabilizar por um educando que está "mergulhado em informações" e que necessita ser preparado para o uso das mesmas. Consideramos, portanto, a importância de uma formação docente que privilegie o uso da informação e também habilite o professor a trabalhar o uso da informação com os seus estudantes. Para esta formação consideramos que o docente tenha conhecimento do conceito de
Information Literacy que no Brasil recebeu diversas traduções: Letramento informacional, Competência Informacional, Habilidade informacional, alfabetização informacional e outros.

Sendo assim, apresentamos os conceitos de oralidade, letramento e letramento informacional, analisando a relevância deste último, para a formação de estudantes da licenciatura, que serão futuros professores e deverão ser capazes de aprender com a informação usando a mesma com autonomia e ética. Na sequência, evidenciamos o lócus e o resultado da pesquisa realizada com oitenta e seis estudantes do Programa Institucional de Bolsa de Iniciação à Docência (PIBID) dos cursos de licenciatura ofertados pelo Instituto Federal de Educação, Ciência e Tecnologia de Rondônia-IFRO, de acordo com o Quadro 1.

\begin{tabular}{|c|c|c|}
\hline & \multicolumn{2}{c}{ Quadro 1 - Cursos de licenciatura ofertados pelo IFRO } \\
$\mathrm{N}^{\text {o }}$ & Curso de licenciatura ofertado & Campus \\
\hline $\mathbf{0 1}$ & Ciências Biológicas & Ariquemes \\
\hline $\mathbf{0 2}$ & Matemática & Cacoal \\
\hline $\mathbf{0 3}$ & Ciências Biológicas & Colorado do Oeste \\
\hline $\mathbf{0 4}$ & Química & Ji-Paraná \\
\hline $\mathbf{0 5}$ & Física & Porto Velho Calama \\
\hline $\mathbf{0 6}$ & Ciências com Habilitação em Química ou & Guajará-Mirim \\
\hline $\mathbf{0 7}$ & Biologia & Vilhena \\
\hline Fonte: Elaborado pelas Autoras, com base em informações coletadas no site do IFRO.
\end{tabular}

\section{LETRAMENTO INFORMACIONAL}

No Brasil o termo Information Literacy ainda não recebeu uma tradução oficial como, por exemplo, em Portugal, onde o termo foi traduzido como Literacia informacional. a palavra Literacia, existe no vocabulário português, mas em nosso país, este termo não existe. Na literatura científica da Ciência da Informação (CI) no Brasil, existem diferentes traduções do termo Information Literacy, realizado por diferentes pesquisadores como, por exemplo: Competência em Informação (Coinfo) utilizada por Costa (2017), Competência Crítica em Informação, utilizado por Brisola e Romeiro (2018), Competência Informacional, utilizado por Almeida (2015) e por fim, Letramento Informacional utilizado por Campelo (2009) e Gasque (2012).

Letramento é uma expressão que hoje vem se especializando para apontar os mais variados modos de apropriação, domínio e uso da escrita como prática social e não como uma simples forma de representação gráfica da língua [...], pois o letramento evoluiu com as novas tecnologias da informação e o [...] Letramento voltou-se para o uso e as práticas e não especificamente para as formas, envolve inclusive todas as formas visuais, como fotos, gráficos, mapas e todo tipo de expressão visual e pictográfica, observável em textos multimodais (MARCUSCHI, 2007, p. 31).

Neste artigo compreende-se o termo Information Literacy como "Letramento Informacional", tanto para fins do estudo, quanto em concordância com a visão de pesquisadores de referência na área da CI, Biblioteconomia e Educação. A exemplo de Gasque (2012), que defende o termo Letramento informacional, como um letramento necessário, desde a formação inicial do educando e defende também, a sua aplicação na formação de alunos do Ensino Básico, Fundamental, Médio e no Ensino Superior. A autora, também criou a "Proposta 
de conteúdos de Letramento Informacional para a Educação Básica e o Ensino Básico" (GASQUE, 2012), voltados para as escolas brasileiras. Na proposta, Gasque (2012), também apresenta os conteúdos e habilidades informacionais, que deverão ser aprendidos pelos educandos brasileiros.

Enfim, podemos afirmar que o Letramento Informacional é uma estruturação sistêmica, com um conjunto de competências que permite ações de: 1 - Localizar, 2 - selecionar, 3 acessar, 4 - organizar, 5 - usar a informação e por fim gerar conhecimento, tudo isso com um único objetivo de aprendizagem: ou seja, o de ajudar o estudante a realizar uma pesquisa escolar, acadêmica ou na tomada de decisão, isto é, o "aprender a aprender" Gasque (2012). A expressão information literacy surgiu pela primeira vez em 1974 e foi cunhada pelo bibliotecário americano Paul Zurkowski e mencionada no relatório intitulado The information service environment relationships and priorities (ZURKOWSKI, 1974).

Neste documento o bibliotecário propôs que os Estados Unidos adotassem o letramento informacional como ferramenta de acesso à informação. Entretanto, esta proposta só se tornou realidade a partir do de 1989, principalmente com o advento da internet e, por fim, com a disponibilização maciça de informações em rede. Esse período também foi marcado pelo fim da União Soviética, que décadas antes influenciou, juntamente com os Estados Unidos, uma corrida armamentista e tecnológica, que desencadeou um fenômeno nunca antes visto na história, a chamada "explosão informacional". De acordo com Gasque (2012):

Para dar conta da grande quantidade de informação, organizá-la e disponibilizá-la, bibliotecas, indústrias e demais unidades de informação começaram a implementar sistemas e aperfeiçoar técnicas que a tornassem acessível com maior rapidez possível. As novas tecnologias da informação e da comunicação transformaram o mundo em uma verdadeira "aldeia global". A informação circula com mais facilidade, em curto espaço de tempo. Já não são necessários grandes esforços para encontrá-la. Cada vez mais, eventos, fenômenos e fatos que ocorrem em vários lugares do mundo são divulgados de forma quase simultânea. Não é preciso mais esperar dias e dias para as notícias chegarem à população em geral, pelos menos em grande parte dos países. Além disso, outros meios, como o rádio, a $\mathrm{TV}$ e as revistas, consolidam-se como transmissores de informação de baixo custo. Em decorrência das demandas econômicas e sociais, as fronteiras territoriais se tornam mais próximas. Esse fenômeno de maior interação entre os países e os povos designase globalização (GASQUE, 2012, p. 25).

A educação mais uma vez passou por mudanças. Agora o conhecimento estava ao alcance de todos e surgiu um novo campo de pesquisa, buscando entender e analisar as técnicas de ensino-aprendizagem e buscar fomentar o desempenho dos estudantes. Destacam-se estudos de realizados desde o início do século XX pelo norte americano Dewey (1859-1952), Jean Piaget (1896-1980), David Ausubel (1918-2008), Lev Vygotsky (1896-1934) e Paulo Freire (1921-1997), dentre outros. Todos esses estudiosos preconizam que os indivíduos devem estar no centro do processo de aprendizagem e que suas experiências devem ser respeitadas como ancoragem para os novos conhecimentos.

As pesquisas sobre processos cognitivos podem auxiliar os educadores na tarefa de ensinar com mais qualidade na sociedade contemporânea e as bibliotecas escolares e universitárias são espaços privilegiados neste processo de capacitação informacional. Dessa forma, para os futuros dentes as bibliotecas dentro das escolas e universidades, jamais devem ser vistas como ilhas, elas são locais primários de busca da informação e têm por objetivo formar cidadãos críticos e autônomos.

Sabemos das dificuldades e do abandono das bibliotecas escolares no Brasil, mas também sabemos que a educação é um ato de coragem, como afirmou Paulo Freire (1999), a educação é um espaço de lutas e conquistas e acreditamos que toda luta tem um começo, inserir práticas educativas de uso da informação dentro da formação dos professores, pode ser um campo fértil, que talvez no futuro venha formação cidadão mais críticos e reflexivos, com uso correto da informação. De acordo com Gasque (2012):

Assim, aprender é mais do que armazenar, memorizar e processar dados. $\mathrm{Na}$ verdade, aprender implica buscar e usar informações, utilizando os incontáveis recursos à disposição, para desconstruir e depois ser capaz de reconstruir uma arquitetura 
conceitual e epistemológica realmente efetiva no entendimento do que está acontecendo hoje no mundo, com intenções de melhorar as condições de vida da humanidade (p. 119).

Portanto nos questionamos: o letramento informacional é importante para a formação dos futuros professores formados pelo IFRO e em especial, como os estudantes do Programa Institucional de Bolsa de Iniciação à Docência (PIBID)? Qual seria o perfil de uso da informação dos mesmos? Esses futuros docentes incentivam seus estudantes a realizarem suas pesquisas escolares com o uso da informação?

O PIBID foi instituído pela Portaria $n^{\circ}$ do Ministério da Educação - MEC, de 12 de dezembro de 2007 e, inicialmente, priorizou o incentivo à formação de professores nas áreas de Física, Química, Biologia e Matemática. Com os resultados positivos o Programa passou a atender a outras áreas e em 2010, foi publicado o Decreto $\mathrm{n}^{\circ} 7.219$, que se tornou o regulamento principal do programa. No ano de 2013 consolidou-se como política pública educacional no âmbito do Ministério da Educação e da CAPES, com a publicação da Lei $\mathrm{n}^{\mathrm{o}}$ 12.796. Os objetivos do PIBID de acordo com a o Decreto ${ }^{\circ}$ 7.219, são:

1 - Incentivar a formação de professores em cursos de nível superior para atuarem na educação básica;

2 - Colaborar para a valorização do magistério;

3 - Elevar a qualidade da formação inicial de docentes de cursos de licenciatura, integrando a educação superior e a básica;

4 - Inserir alunos de licenciatura no cotidiano escolar, dando-lhes a oportunidade não só de participar de experiências metodológicas, tecnológicas inovadoras e interdisciplinares que visem à superação de problemas no processo de ensino-aprendizagem, mas também de criar tais experiências;

5 - Mobilizar professores de escolas públicas como responsáveis pelos processos de formação inicial de futuros docentes;

6 - Colaborar para a articulação entre teoria e prática, ambas essenciais à formação de professores.

De acordo com Lima; Bezerra (2014):

Os bolsistas do PIBID são escolhidos por meio de processos de seleção promovidos pelas instituições que oferecem os cursos de licenciatura. A Capes concede as seguintes modalidades de bolsa: bolsa para licenciados; para coordenador institucional; para coordenador de área; para professor supervisor. O Programa oportuniza aos licenciados a convivência com a realidade escolar, desde o início da graduação, permitindo-lhes conhecer seu futuro campo de atuação. Cabe ao professor supervisor e ao coordenador de área auxiliar os bolsistas no planejamento das aulas, em que eles vivenciam a prática de sua futura profissão ( $\mathrm{p}$. 179).

Portanto, o PIBID é uma política pública que visa formar docentes capacitados de nível superior para atuarem na Educação Básica e por fim melhor a qualidade da formação inicial dos futuros docentes, integrando a Educação Superior e a Básica.

\section{O INSTITUTO FEDERAL DE EDUCAÇÃO DE RONDÔNIA-IFRO}

$\mathrm{Na}$ primeira década do século XXI a educação brasileira vivenciou a criação e fortalecimentos das redes de escolas técnicas federais. Os institutos Federais têm como base os eixos do Ensino, Pesquisa e Extensão, com foco no ensino técnico e tecnológico. $\mathrm{O}$ Instituto Federal de Educação, Ciência e Tecnologia de Rondônia (IFRO) faz parte do programa de expansão da Rede Federal de Educação Profissional, Científica e Tecnológica, do Ministério da Educação (MEC). Os IFs estão distribuídos por todo o território brasileiro, funcionam em estrutura multicampi e oferecem cursos de Educação Básica, Profissional e de Educação Superior (BRASIL, 2008b), tendo basicamente 50\% de suas vagas destinadas a cursos técnicos e $20 \%$ destinadas a cursos superiores (tecnologia, licenciatura, bacharelado, pós-graduação stricto sensu e lato sensu). Os cursos oferecidos pelos campi procuram adaptar-se às necessidades profissionais, sociais e culturais das regiões onde estão inseridos (OLIVEIRA; AMARAL, p. 2, 2012).

Nosso lócus de pesquisa foi o Instituto Federal de Educação, Ciência e Tecnologia de Rondônia-IFRO, com uma amostra de oitenta e seis estudantes do Programa Institucional de Bolsa de Iniciação à Docência (PIBID) dos diversos campi. A metodologia do trabalho consistiu em uma pesquisa bibliográfica e utilizados questionários como instrumento de coleta de dados com perguntas abertas e fechadas aplicados aos estudantes bolsistas do 
PIBID que participavam do V Seminário do programa que ocorreu no ano de 2016 nos dias 08, 09 e 10 de novembro, no Campus Porto Velho-Calama. O objetivo do questionário foi verificar o perfil de uso informação dos futuros professores e como pesquisam para coletar informações para ministrar suas aulas, experimentos laboratoriais e projetos de pesquisas trabalhados no PIBID. Os cursos de Licenciatura ofertados pelo IFRO, analisados foram: Ciências Biológicas, matemática, Química, Física e Ciências com Habilitação em Química ou Biologia.

Nosso questionário foi intitulado: "Como os alunos do PIBID pesquisam para coletar informações para ministrar suas aulas, experimentos laboratoriais e projetos de pesquisa?" No total foram nove perguntas feitas aos participantes, a primeira foi sobre o nome do estudante, mas esta questão foi descartada, pois não fez parte do objetivo da pesquisa.

Com a segunda questão, idade dos participantes, queríamos verificar a faixa etária dos estudantes do PIBIB do IFRO. Podemos observar no gráfico de número 01 , que a maioria dos participantes é jovem com idade variando dos 17 anos aos 27 anos (Gráfico 1).

Gráfico 1- Idade dos participantes da pesquisa.

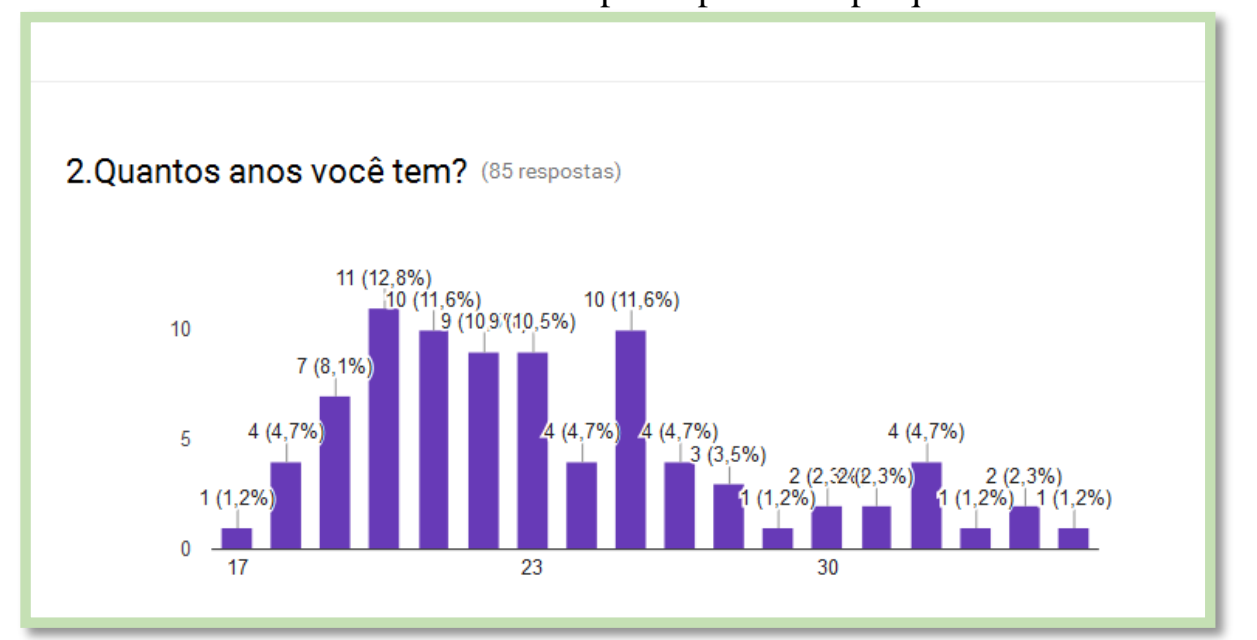

Fonte: Elaborado pelas autoras, 2017.

A terceira questão, sobre o sexo dos participantes, procuramos verificar a participação tanto masculina quanto feminina nos cursos ofertados e o resultado não foi uma grande surpresa, pois fica evidente que na área da Educação, há uma participação maior de mulheres educadoras, $69,4 \%$ dos participantes eram do sexo feminino e apenas $30 \%$ masculino (Gráfico 2).

Gráfico 2 - Sexo dos participantes da pesquisa.

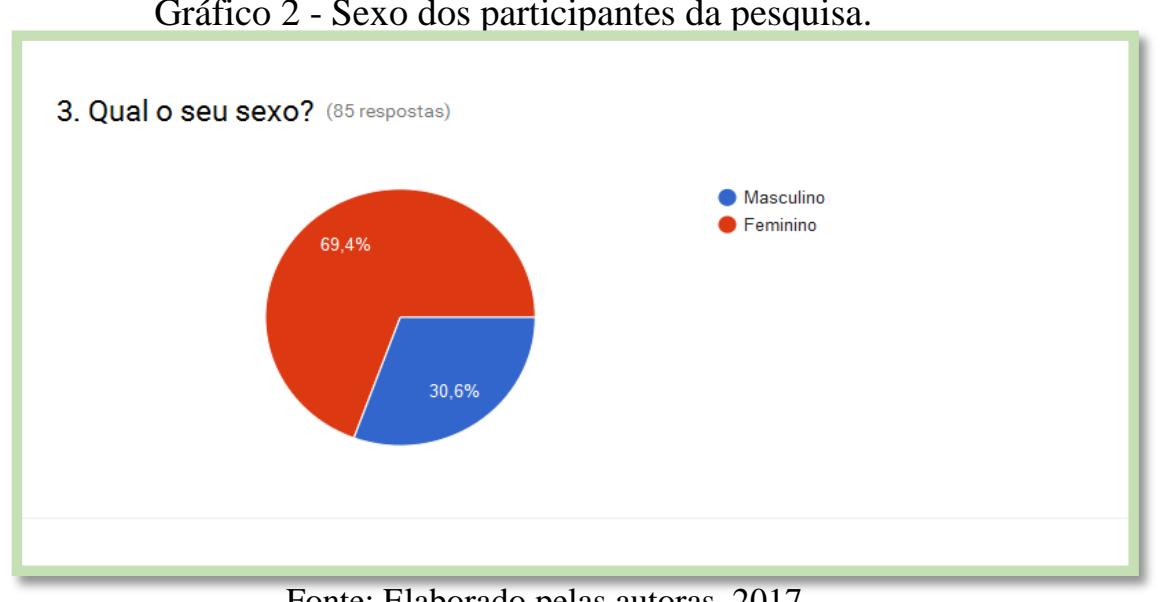

Fonte: Elaborado pelas autoras, 2017 
De acordo com o MEC (2007, p. 1):

Chama a atenção o fato de mais mulheres do que homens ingressarem na universidade na faixa etária apropriada (18 a 24 anos). A menor presença de homens na graduação, apesar de serem maioria na sociedade na fase do vestibular, parece indicar uma opção masculina precoce pelo mercado de trabalho. Estaria a sociedade reafirmando o clichê de que a tarefa de buscar o sustento da família cabe mais a eles que a elas? Merece destaque a trajetória das mulheres na graduação: quando deixam o corpo discente, elas representam sete pontos percentuais a mais do que quando ingressam no campus, indicando que a sua taxa de sucesso é maior que a dos homens e que, por isso mesmo, a maioria observada no momento do ingresso $(56,4 \%)$ se torna ainda mais sólida na formatura $(63,4 \%)$ (BRASIL, 2007, p. 1).

$\mathrm{Na}$ quarta questão procuramos conhecer e verificar a qual campus do IFRO o estudante pertencia, verificamos que os campi que mais enviaram estudantes para participar do evento, foram os campi de Ji-Paraná, seguido pelo campus IFRO de Colorado do Oeste. Logo em seguida tivemos a presença de estudantes dos campi de Ariquemes, Vilhena e Campus Porto Velho Calama (Gráfico 3).

Gráfico 3 - Campus IFRO dos participantes da pesquisa

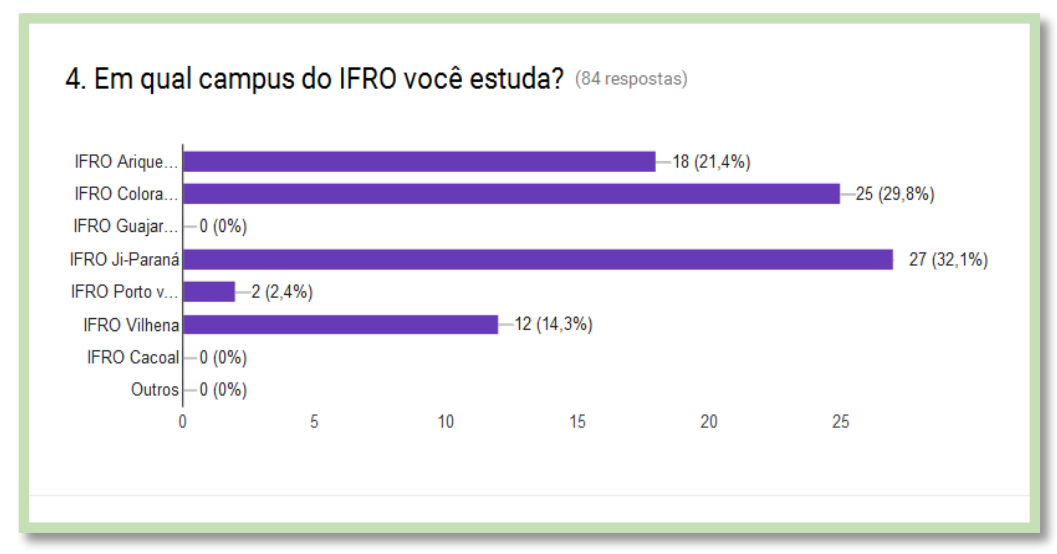

Fonte: Elaborado pelas autoras, 2017.

Na quinta questão procuramos conhecer os motivos que levaram os estudantes a escolher o curso de licenciatura. Nessa questão obtivemos 72 respostas, onde $43,1 \%$ afirmaram que a escolha foi por gostar do curso. $34,7 \%$ dos estudantes informaram que escolheram o curso para serem professores (Gráfico 4). Sobre a escolha recair na opção pelo magistério temos que:

Os cursos mais procurados pelos homens são relativos a engenharia, tecnologia, indústria e computação; pelas mulheres, são relativos a serviços e educação para a saúde e para a sociedade (secretariado, psicologia, nutrição, enfermagem, serviço social, pedagogia). Essa tendência se mantém nos mestrados, doutorados e na própria docência da Educação Superior (BRASIL, 2007, p. 1).

Um grupo de estudantes afirmou que a escolha do curso foi feita tendo em vista o mercado de trabalho, com $18,1 \%$. Por fim, destacam-se outros motivos de escolha da licenciatura e os entrevistados informaram que estavam fazendo a graduação com o objetivo de passar em um concurso público, como por exemplo, os estudantes de Biologia, porque querem trabalhar em órgãos públicos como o Instituto Brasileiro do Meio Ambiente e dos Recursos Naturais Renováveis - IBAMA (Gráfico 4). 
Gráfico 4- Escolha do curso pelos participantes da pesquisa.

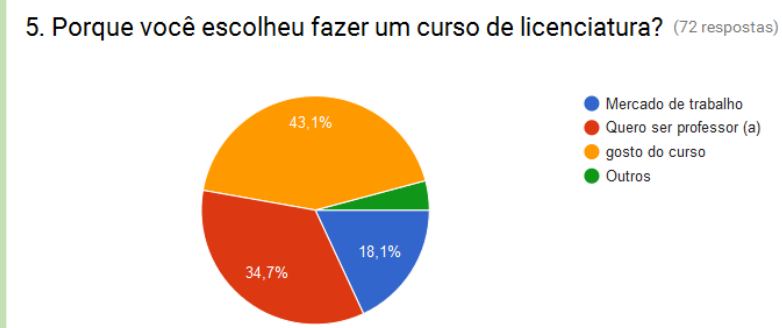

Fonte: Elaborado pelas autoras, 2017.

Na quinta questão buscamos verificar quais os cursos mais atendidos pelo PIBID dentro do IFRO e que estavam participando do evento.
Averiguamos que a maioria dos estudantes eram do curso de Ciências Biológicas, 50\% dos participantes (Gráfico 5).

Gráfico 5- Cursos de Licenciatura dos participantes da pesquisa.

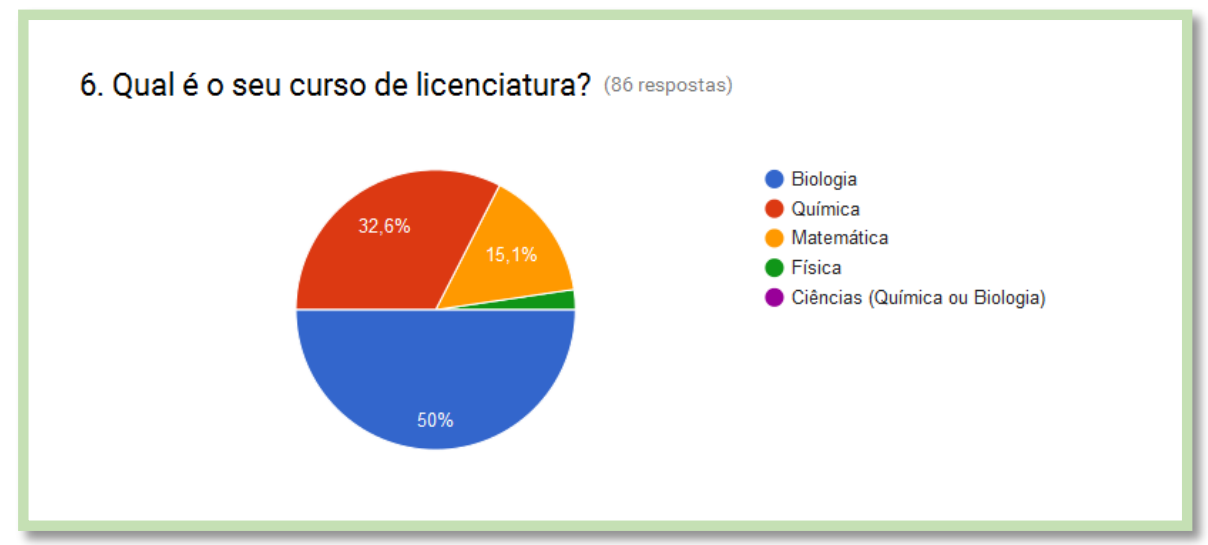

Fonte: Elaborado pelas autoras, 2017.

Por fim, na sétima questão procuramos verificar o perfil informacional dos estudantes. Isso ocorreu, por meio da análise das fontes de informação utilizadas pelos mesmos e como organizam as suas aulas com estas fontes. A questão elaborada foi a seguinte: "Onde você coleta informações para organizar suas aulas nos estágios em sala de aula?" Foram disponibilizadas cinco opções de fontes informacionais para os estudantes escolherem (Gráfico 6):

1- Livro didático;

2- Livros da biblioteca da escola;
3- Livros da Biblioteca do IFRO;

4- Internet (Google, Youtube, e outros);

5- Livros da graduação, indicados pelo professor;

6- Enciclopédias;

7- Manuais;

8- Outros 
Gráfico 6- Fonte de informações dos participantes da pesquisa

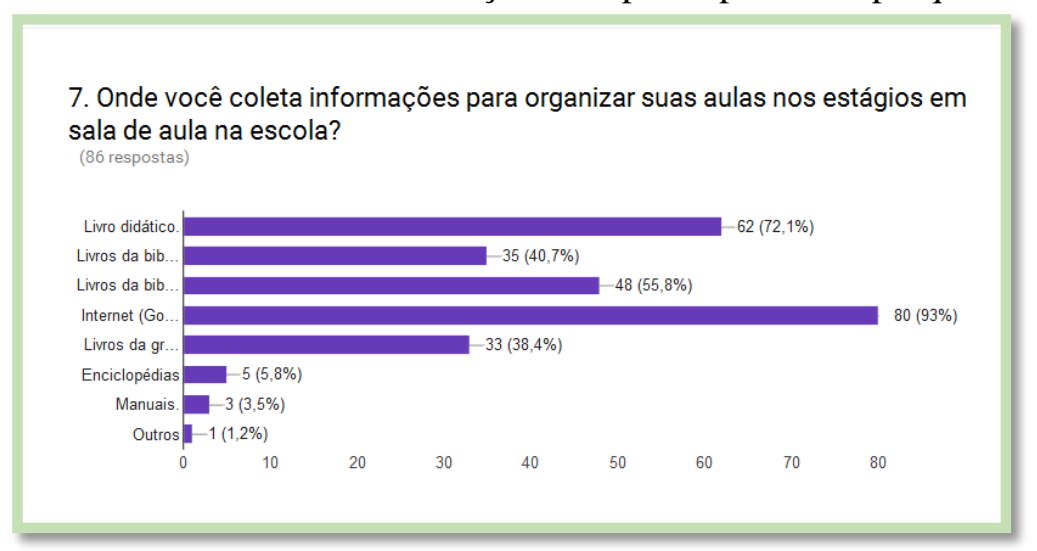

Fonte: Elaborado pelas autoras, 2017.

No primeiro item, Livros Didáticos, identificamos que os futuros professores coletam informações voltadas quase que exclusivamente no livro didático. Observamos que os mesmos mantêm a tradicional primazia do educador sobre este material informacional. $72 \%$ dos estudantes responderam que organizam suas aulas do estágio com o uso do livro didático. Isso nos leva a refletir com Silva (2003), que afirma:

Aulas exclusivamente expositivas ou rigidamente obedientes ao comando do livro didático, por vezes considerado a sétima maravilha do mundo, impedem a participação de outros elementos no processo de ensinoaprendizagem. Dessa forma há poucas ocasiões para a utilização da biblioteca escolar, salvo seu uso clássico como "espaço de castigo" ou "espaço da cópia” (SILVA, 2003, p. 19).

Nesta pesquisa observamos que na formação de professores reafirma-se o uso do livro didático como ferramenta principal de uso da informação com os estudantes da rede pública. Nos questionamos se essa formação está sendo feita para realmente inserir o estudante e o professor na sociedade do conhecimento? A resposta provavelmente é não. O professor e a escola da "era da informação" deve buscar outros produtos informacionais para auxiliar no processo de ensino-aprendizagem, mas a realidade alertada 14 anos atrás por Silva (2003), ainda ocorre nas escolas brasileiras e é o reflexo da formação dos professores brasileiros.

Mas observamos também que 40,7\% utilizam os materiais da biblioteca da escola em que estagiam e $55,8 \%$ utilizam as bibliotecas do IFRO para coletar informações e organizar suas aulas (Gráfico 6). Isso ocorre em virtude do IFRO oferecer acervos e bibliotecas que buscam ofertar a seus estudantes materiais de qualidade, mas além destes, defendemos que as práticas de letramento informacional poderiam ser aplicadas e melhorariam ainda mais a formação dos estudantes e o bibliotecário deveria ter consciência de sua importância, haja vista que este é o profissional melhor capacitado dentro da instituição para o uso e disseminação da informação.

Nas bibliotecas educacionais é necessário
conhecer a proposta pedagógica da
instituição, caracterizar o ambiente (efetuar o
diagnóstico da instituição) e identificar o
perfil do uso e das necessidades da
comunidade educacional para estabelecer
quais as demandas informacionais e propor
serviços e produtos qualitativos na instituição
educacional (BLATTMAN, ALMADA,
2015, p. 7).

Enfim, demonstrado a força da informação multimídia, a internet foi o item mais utilizado pelos estudantes na coleta de informações para a organização das aulas, a internet além de facilitar o encontro de diversas informações, possui a mesma em diversas formas: vídeos, imagens, músicas, etc. Neste item verificamos que $93 \%$ dos estudantes utilizam a rede de internet para construir suas aulas (Gráfico 6).

Portanto, o uso da internet aliado ao uso dos livros didáticos e dos livros das bibliotecas são fontes de informações que os futuros profissionais da educação estão utilizando para organizar suas aulas. O que questionamento 
que fazemos é sobre a importância da potencialização desta realidade. é possível aliar então práticas de Letramento Informacional dentro da formação desses professores, para ajudar tanto na sua formação como na organização de suas aulas? Esta questão nos levou a questionar a importância do Bibliotecário e da Biblioteca Universitária, de como parcerias de formação e oficinas de Competência Informacional, poderiam ajudar em uma formação mais sólida dos futuros profissionais de ensino.

Na sétima questão de nossa pesquisa, procuramos entender quem orientava estes estudantes sobre a pesquisa escolar e organização das aulas dentro do IFRO. 86,7\%, afirmou que os professores os ajudavam, 3,6\% informou que pediu apoio aos bibliotecários da rede de bibliotecas do IFRO (Gráfico 7).

Gráfico 7- Orientação participantes da pesquisa

8. Você recebeu alguma orientação para fazer pesquisa escolar? (83 respostas)

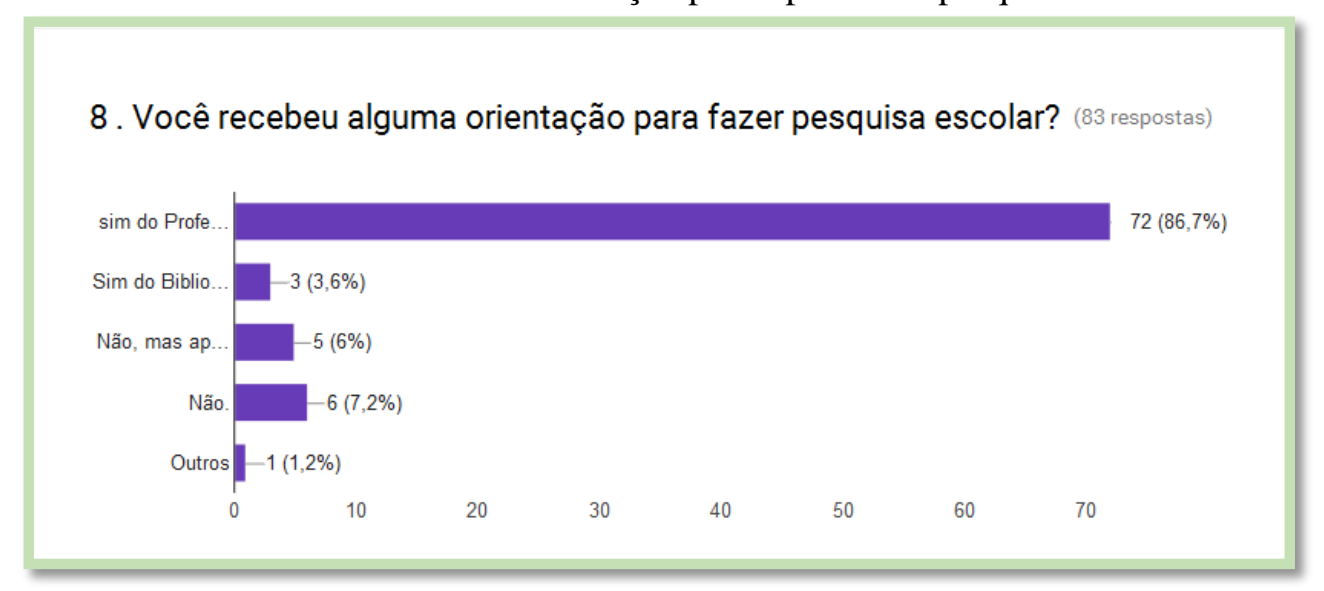

Fonte: Elaborado pelas autoras, 2017

Isto para nós foi um dado importante, pois, verificamos a importância do profissional bibliotecário dentro do IFRO, porém observamos que este muitas vezes, foca seus esforços na parte administrativa e técnicas biblioteconômicas e é evidente que este profissional tem um campo rico de atuação a ser trabalhado e desenvolvido da instituição. De acordo com Martins (2001):

O bibliotecário se transformou, por consequência, nessa última década em técnico puro - com todos os inconvenientes e todas as virtudes dessa condição. Entre as últimas assinalemos a sua maior eficiência, garantida pela organização racional do trabalho; a exclusividade da atenção que consagra ao seu oficio, o que evita as sempre deploráveis dispersões de interesse; a sua consciência profissional cada vez mais desenvolvida; o seu prazer em desempenhar funções que correspondam aos seus dons mais íntimos (p. 332).

O bibliotecário tem a função primordial de ajudar os estudantes a serem competentes no uso da informação como afirma Gasque (2012) "aprender a aprender" e por fim também ser um auxiliar no trabalho do docente seja em sala de aula, bibliotecas ou outros espaços.

Para finalizar as questões da pesquisa, em nossa nona pergunta, fizemos a seguinte questão aos estudantes: Você em suas aulas na escola já orientou alunos a fazer pesquisa escolar? Esta pergunta teve o propósito de colher informações dos estudantes de acordo com suas observações. No total foram 61 respostas, onde trinta e um licenciandos responderam que ainda não haviam orientado estudantes, pois ainda não haviam indo para as escolas estagiar (Quadro 1).

Quadro 1 - Orientações à pesquisa escolar realizada pelos estudantes do PIBID. Você costuma orientar os estudantes a fazer pesquisa escolar?

\begin{tabular}{|c|c|}
\hline Respostas & Quantidade \\
\hline Não & 30 \\
\hline Sim & 04 \\
\hline Sim, feira de ciências & 02 \\
\hline
\end{tabular}


Respostas dos estudantes:

Ainda não orientei, mas vou pensar no assunto.

Sim. Foi muito proveitoso e assim incentivamos os alunos.

Sim. Se mostraram muito interessados, pois geralmente não tem essa vivencia e se mostram muito participativos, por ex., produção de formigas e horta escolar.

Sim, orientando no desenvolvimento de pesquisas para a elaboração de projetos realizados como feira cultural, gincanas e palestras, utilizando como ferramenta internet e livros da biblioteca, aulas práticas também.

Sim, pesquisa sobre projeto PIBID desenvolvido nas escolas.

Sim, orientei ele a buscarem livros na biblioteca para ajudar, assim como na internet, para complementar seus conhecimentos.

Sim, buscando instigá-los a buscar novos conhecimentos.

Sim benéfico e enriquecedor para o aluno.

Sim, incentivei a buscar informação no livro didático e na web.

Já sim, foi maravilhoso ficaram felizes os olhos brilhando.

Sim. Trabalhei com projeto sobre seminário e pedimos para pesquisar em várias fontes diversificadas para montar os slides. Esta atividade ocorreu na fase de participação do estágio supervisionado.

Sim, incentivando eles a buscar o conhecimento, não só na sala de aula, mas na internet e em bibliotecas.

Sim, foi bem bacana observamos a interação entre os alunos.

Sim, devido ao incentivo os alunos sempre buscam realizar o que se é pedido dentro da sala de aula.

Sim, já orientei, por exemplo, feira de química. Solicitei que os alunos buscassem experimentos em sites e ainda levei aos alunos artigos que continham experimentos explicativos e fáceis de serem executados.

Sim, foi interessante, pois eles se sentiram motivados e gostaram de ser curiosos e aplicá-los.

Sim, muito proveitoso para os alunos em diferentes campos do conhecimento.

Sim, foi bem satisfatório houve grande evolução.

Em todas as minhas aulas até hoje houve grande interesse e participação dos alunos e para a minha orientação todos buscaram com interesse.

Sim, foi muito gratificante ver que os alunos puderam pôr em prática todas as orientações que você passou bem interessante ver que eles se interessaram pela pesquisa.

Sim, já ministrei uma palestra para os alunos de como fazer uma pesquisa básica, como estruturar o trabalho de acordo com a ABNT (formatação entre outras coisas). Foi muito bom essa experiência, os alunos gostaram, pois tinham muitas dificuldades quando o professor passava algum trabalho.

Sim. Incentivando a criação e inovação de ideias.

Sim, foi muito prazeroso, pois despertou muito a atenção dos alunos.

Quatro graduandos responderam que iriam pensar no assunto e que estavam aguardando para orientá-los. As outras respostas variaram entre orientação para a organização de feira de ciências, coletamos duas respostas. Alguns licenciandos responderam que sim para a solicitação de pesquisa escolar a seus estudantes e ainda relataram as atividades realizadas com entusiasmo. Essas respostas foram importantes o que nos levou a refletir, ainda mais, sobre a importância da pesquisa escolar e o letramento informacional dentro da escola, como ferramentas e métodos de aprendizagem e de que é possível para o bibliotecário e o professor realizarem atividades conjuntas para a melhoria da educação e isso pode começar também na formação do professor.

Para isso damos destaque para três falas de estudantes do PIBID:

"Sim, já ministrei uma palestra para os alunos de como fazer uma pesquisa básica, como estruturar o trabalho de acordo com a ABNT (formatação entre outras coisas). Foi muito boa essa experiência, os alunos gostaram, pois tinham muitas dificuldades quando o professor passava algum trabalho". 
Esse comentário revela a principal função de um agente que fomenta o Letramento Informacional dentro da escola: ensinar às crianças deste de cedo a importância do uso e disseminação correta da informação cientifica. Nela, o futuro profissional da educação, mostrou um aspecto esperado de profissionais que buscam inserir seus estudantes dentro da Sociedade do Conhecimento. Lorena (2014) ressalta que:

A competência em informação é uma característica importante na sociedade contemporânea. Porém, a grande disponibilidade de informação, em uma diversidade de meios, traz como efeito colateral a questão de confiabilidade da informação. Por outro lado, a competência em informação é interdisciplinar, envolvendo diversas áreas de conhecimentos, ambientes e níveis educacionais, sendo também base para a autoaprendizagem (LORENA, 2014, p. 18).

Outro graduando informou que usou a internet como fonte de informação, para instigar os estudantes a realizar pesquisas para uma feira de química:

"Sim, já orientei, por exemplo, feira de química. Solicitei que os alunos buscassem experimentos em sites e ainda levei aos alunos artigos que continham experimentos explicativos e fáceis de serem executados".

Nesta fala verificamos o interesse do futuro docente em oferecer aos alunos fontes de informações confiáveis, realizando assim um letramento informacional, para uso de informações de valor cientifico para os seus estudantes.

Enfim, o último relato o graduando pediu aos estudantes que utilizassem várias fontes de informação:

"Sim. Trabalhei com projeto sobre seminário e pedimos para pesquisar em fontes diversificadas para montar os slides. Esta atividade ocorreu na fase de participação do estágio supervisionado.

Aqui o futuro profissional pediu apresentações de trabalho com utilização de diferentes fontes de informação aos estudantes, buscando ampliar a gama de conhecimentos que podem ser aprendidos pelos discentes.

\section{CONSIDERAÇÕES FINAIS}

Em síntese, observou-se que mesmo utilizando métodos tradicionais como fontes de informação, como por exemplo o livro didático, parte dos futuros docentes, demonstraram que estão inseridos na Sociedade da Informação e que possuem um interesse maior, no uso de diferentes fontes de informação. Entretanto, parte dos licenciandos ainda mantém o tradicional uso da informação, com foco exclusivo no livro didático, o que norteia a necessidade da aplicação de práticas que auxiliem o futuro docente no uso letrado da informação.

Portanto em vista do resultado da pesquisa sugerimos ao IFRO, que busque uma atenção especial na formação dos professores para o uso da informação. Fizemos também uma observação sobre os serviços ofertados pelas bibliotecas do IFRO, no sentido de uma maior atuação do profissional bibliotecário como educador e disseminador de programas e práticas de Competências Informacionais para a melhoria do ensino. Sabemos que a discussão da importância de Práticas de Letramento Informacional no IFRO só está na fase inicial, mas vemos um futuro promissor de atuação dos bibliotecários (as) e o uso de suas bibliotecas, juntamente com os professores. Ainda é necessário estreitar os laços do conceito de Letramento Informacional e a Biblioteca Escolar, para os docentes e a equipe pedagógica, ou seja, expressar sua importância e de como essas práticas podem auxiliar na melhoria do ensino.

A biblioteca tem o potencial de fazer a diferença dentro de uma instituição de ensino, principalmente uma instituição que visa a formação de cidadãos capazes de agir e utilizar a informação criticamente em busca de uma sociedade sustentável respeitando a sua história e o contexto onde está inserido. Contudo um dos primeiros passos a ser dado é no sentido da biblioteca e do Bibliotecário conquistarem seu espaço de atuação dentro dos cursos de Licenciatura do IFRO, deixando de ser apenas um apêndice da escola e passar a refletir a seriedade dos objetivos educacionais aqui expostos. Dessa forma, o Letramento Informacional poderá ser um dos componentes de dinamização das atividades, fazendo da biblioteca um lugar realmente útil para a comunidade onde está inserida. E como afirma Le Coadic (1996, p. 110), os bibliotecários devem se preocupar com "[...] a criação, armazenamento, comunicação e uso da informação", examinando os seus futuros papéis e se aproximando cada vez mais da 
informação e "[...] mais distantes do livro, do documento e do objeto".

\title{
INFORMATION LITERACY AND TEACHER TRAINING: A LOOK AT THE GRADUATES OF THE UNDERGRADUATE COURSES OF THE INSTITUTE FEDERAL DE RONDÔNIA
}

Abstract

\begin{abstract}
This study presents the research carried out with eighty-six students of the undergraduate courses offered by the Federal Institute of Education, Science and Technology of Rondônia, Brazil (IFRO) who take part in the Institutional Program of Initiatives for Teaching (PIBID). It analyzes the concepts of literacy and information literacy and discusses its relationship with teacher education. As a data collection tool, questionnaires with open and multiple choice questions were answered by PIBID scholarship holders. As a result of the research, it was observed that even when traditional methods were used as sources of information, such as the textbook, some of the future teachers showed that they are active in the Information Society and that they have great interest in using different sources of information. However, some graduates still maintain the traditional use of information, with an exclusive focus on the textbook, which leads to the need of applying practices that help the future teacher in the literate use of information.
\end{abstract}

Keywords: Information literacy. PIBID. Federal Institute of Rondônia.

\section{REFERÊNCIAS}

ALMEIDA, Jobson Louis Santos. A biblioteca como organização aprendente: 0 desenvolvimentismo de competências em informação no Instituto Federal de Educação, Ciência e Tecnologia da Paraíba. 2015. 122 f. Dissertação (Mestrado) - Programa de Pós Graduação em Organizações Aprendentes. João Pessoa: Universidade Federal da Paraíba, 2015.

AURÉLIO. Dicionário Online. 2017. Disponível em: < https://dicionariodoaurelio.com/>. Acesso em: 03 jul. 2017.

BAPTISTA, Mônica Correia. A Linguagem escrita e o direito à educação na Primeira Infância. Consulta Pública. MEC, 2010.

BURKE, Peter. Uma história social do conhecimento: de Gutemberg a Diderot. Rio de Janeiro: Jorge Zahar, 2003. 241p.

BRASIL. MEC. SEF. Parâmetros curriculares nacionais: língua portuguesa. MEC: Brasília, 1997. (p. 35-49).
Dilvo Ristoff. Ministério da Educação - MEC. A trajetória da mulher na educação brasileira. 2007. Disponível em: <http://portal.mec.gov.br/ultimasnoticias/202-264937351/5710-sp1216879868>. Acesso em: 20 jul. 2017.

BRISOLA, Anna Cristina; ROMEIRO, Nathália Lima. A competência crítica em informação como resistência: uma análise sobre o uso da informação na atualidade.

Revista Brasileira de Biblioteconomia e Documentação, São Paulo, v. 14, n. 3, p.6887, 01 dez. 2018. Semestral. Disponível em: <file:///C:/Users/1921139/Desktop/COMPET \%C3\%8ANCIA\%20CR\%C3\%8DTICA\%20 DA\%20INFORMA\%C3\%87\%C3\%83O/105 4-38>. Acesso em: 07 out. 2018.

CAMPELLO, Bernadete Santos et al. A biblioteca escolar: temas para uma prática pedagógica. 1.ed. Belo Horizonte: UFMG, 2001.

CAMPELLO, Bernadete Santos. Letramento Informacional no Brasil: práticas educativas de bibliotecários em escolas de Ensino Básico. Tese (Doutorado em Ciência da Informação) - Escola de Ciência da 
Informação. Belo Horizonte: Universidade Federal de Minas Gerais, 2009.

COSTA, Célia Revilândia. A Competência em Informação (Coinfo) na perspectiva da educação inclusiva. 2017. $223 \mathrm{f}$. Tese (Doutorado em Ciências da Informação) Faculdade de Ciência da Informação. Brasília: Universidade de Brasília, 2017. Disponível em:

<http://repositorio.unb.br/handle/10482/2453 0>. Acesso em: 09 nov. 2018.

BLATTMANN, Úrsula; ALMADA, Magda. Biblioteca no ambiente educacional e a sociedade da informação. Disponível em: $<$ https://www.academia.edu/3034276/Bibliote ca no ambiente educacional ea sociedade da_informa\%C3\%A7\%C3\%A3o>. Acesso em: 23 jul. 2017.

CERVO, Amado L., BERVIAN, Pedro A., SILVA, Roberto da. Metodologia Científica. 6.ed. São Paulo: Pearson, 2007.

FREIRE, Paulo. Educação como prática da liberdade. $23^{\mathrm{a}}$ ed. Rio de Janeiro: Paz e Terra, 1999.

GASQUE, Kelley Cristine Gonçalves Dias. Letramento Informacional: pesquisa, reflexão e aprendizagem. Brasília: Faculdade de Ciência da Informação / Universidade de Brasília, 2012. 175 p.

GALVÃO, Ana Maria de Oliveira; BATISTA, Antônio Augusto Gomes. Oralidade e escrita: uma revisão. Disponível em:

http://www.scielo.br/pdf/cp/v36n128/v36n12 8a07.pdf Acesso 03/02/2011. Acesso em: jul. 2017.

HAVELOCK, Eric. A equação oralidade cultura escrita: uma fórmula para a mente moderna. In: OLSON, D. R; TORRANCE, N. (Org.). Cultura escrita e oralidade. 2. ed. São Paulo: Ática, 1997. p. 17-34.

IFRO. Institucional. Porto Velho, 2015.

Disponível em:

<http://www.ifro.edu.br/site/?page_id=9>.

Acesso em: 23 dez. 2017.

IFRO. Regimento Geral do IFRO. Porto

Velho, 2011. Disponível em: <

http://www.ifro.edu.br/site/wp-
content/uploads/2009/04/Regimento-

Geral.pdf>. Acesso em: 23 jul. 2017.

LIMA, Sara Passos de; BEZERRA, Mauro Guilherme Ferreira. O PIBID de Física do Instituto Federal de Educação, Ciência e Tecnologia de Rondônia sob o olhar da coordenação de área. Polyphonía, Goiânia, v. 25, n. 1, p.177-188, jan. 2014. Semestral. Disponível em:

〈https://www.revistas.ufg.br/sv>. Acesso em: 26 jul. 2017.

LORENA, Arthur Mendes. Uma Oficina para Desenvolvimento de Competência em Informação dos Funcionários do Crea-DF. Monografia (Graduação) - Universidade de Brasília, Brasília, 2014.156 p.

LE COADIC, Yves-François. A ciência da informação. Brasília: Briquet de Lemos/Livros, 1996. 119p.

MARCUSCHI, Luís Antônio et al. Fala e escrita. Belo Horizonte - Mg: Autêntica, 2007. 208 p.

MARTINS, Wilson. A palavra escrita: história do livro, da imprensa e da biblioteca. 3.ed. São Paulo, SP: Ática, 2001.

MEC. Centenário da Rede Federal de Educação Profissional e Tecnológica. Brasília, 2009. Disponível em: $<$ http://portal.mec.gov.br/setec/arquivos/cente nario/historico educacao profissional.pdf $>$. Acesso em: 01 jul. 2017.

MORE: Mecanismo online para referências, versão 2.0. Florianópolis: UFSC Rexlab, 2013. Disponível em:

<http://www.more.ufsc.br/>. Acesso em: 21 Nov. 2018.

RIBEIRO, Ana Elisa; COSCARELLI, Carla Viana. Termos de alfabetização, leitura e escrita para educadores: Letramento digital. 2018. Disponível em:

$<$ http://www.ceale.fae.ufmg.br/app/webroot/g lossarioceale/verbetes/letramento-digital >.

Acesso em: 21 nov. 2018.

SANTOS, Leonor Werneck dos. Oralidade e escrita nos PCN de língua portuguesa.

Disponível em: < http://www.filologia.org.br/viiisenefil/08.html >. Acesso em: 01 jul. 2017. 
SILVA, Waldeck Carneiro da. Miséria da

biblioteca escolar. 3. ed. São Paulo: Cortez, 2003. 119 p. (Questões da nossa época).

VYGOTSKI, Lev S. El problema del edad. In: Obras Escogidas IV: Psicología infantil. Madrid: Visor, 1996.

\section{ZURKOWSKI, P. G. The Information}

Service Environment Relationships and

Priorities: report 5. Washington, D. C.,

National Commission on Libraries and

Information Science, Nov 1974. Disponível

em:

$<$ http://files.eric.ed.gov/fulltext/ED100391.pd f $>$. 